\title{
Heat Induced Pre-Treatment Technologies for Lignocellulosic Biomass. A Comparison of Different Processes and Techniques
}

\author{
Marvin Scherzinger ${ }^{1 *}$, Martin Kaltschmitt ${ }^{1}$ \\ ${ }^{1}$ Hamburg University of Technology (TUHH), Institute of Environmental Technology and Energy Economics \\ (IUE), Eissendorfer Strasse 40, 21073 Hamburg, Germany \\ * Corresponding author's e-mail: marvin.scherzinger@tuhh.de
}

\begin{abstract}
In order to overcome several obstacles when using lignocellulosic biomass as solid fuel, different heat induced pre-treatment techniques are available. Such a pre-treatment can be realized either within a gaseous or within a hydrothermal or vapothermal atmosphere. Below, the main reactions, occurring in the respective atmosphere at temperatures below $300^{\circ} \mathrm{C}$, typical for such a pre-treatment, are discussed. Different pre-treatment techniques realized at this temperature range were introduced, characterized and compared with each other. This comparison included the current state of research, the market proximity, the process parameters as well as applicable educts and product properties.
\end{abstract}

Keywords: hydrothermal carbonization, vapothermal carbonization, torrefaction, autoclave pre-treatment, lignocellulosic biomass

\section{INTRODUCTION}

Biogenic energy carriers provide around 11 to $15 \%$ of the global primary energy; thus, biomass is the most widely used renewable energy carrier in the world (IEA, 2017). The reason for this is that biomass is available almost everywhere throughout the world - or at least where most of the people live on this globe. Furthermore, biomass is a versatile energy source; it can be converted into solid, liquid and gaseous fuels and can both be used for heat and electricity generation. Furthermore, biomass is not fluctuating, as is the case wind energy or solar radiation; the solar energy is stored in biomass. Additionally, biomass can typically be stored easily without significant losses; this can also be realized on the large scale. However, compared to fossil sources of energy like crude oil and hard coal, biomass shows some significant drawbacks including heterogeneous composition, relatively low bulk density, high water content and low heating value. Therefore, in recent years, different techniques have been developed in order to improve the fuel properties especially of solid biofuels (e.g., by lowering its water content, by modifying its chemical and physical properties).

Against this background, this paper aims at assessing and characterizing the most common heat-induced pre-treatment technologies for solid biofuels (i.e. lignocellulosic biomass) realized within a temperature range up to $300^{\circ} \mathrm{C}$. Namely, these are torrefaction, hydrothermal carbonization (HTC) and vapothermal carbonization (VTC). Furthermore, the autoclave pre-treatment is introduced. Subsequently, the techniques were compared with each other and the similarities as well as differences were identified. Additionally, the effect of these different pre-treatment options was discussed in detail. The composition of lignocellulosic biomass was first presented in detail as a basis for the following explanations.

\section{COMPOSITION OF LIGNOCELLULOSIC BIOMASS}

Below, the elemental and molecular structure of lignocellulosic biomass was discussed, since 
structural changes are a key driver in improving biomass combustion properties.

The main components of lignocellulosic biomass are: carbon $(\mathrm{C})$, oxygen $(\mathrm{O})$ and hydrogen (H). About 90 wt.- $\%$ of the organic dry matter content of biomass is composed of the $\mathrm{C}$ and $\mathrm{O}$ elements; $\mathrm{H}$ contributes as the third-largest element with about 6 wt.- $\%$ to its composition. Furthermore, lignocellulosic biomass contains different shares of trace elements which can be divided into macro- and micro-nutrients (Kaltschmitt, Hartmann \& Hofbauer, 2016).

At the molecular level, lignocellulosic biomass is composed of 3 different biopolymers, namely cellulose, hemicellulose and lignin. Their percentages are highly dependent on the respective plant species (e.g., woody or herbaceous biomass), the plant part (e.g., leaves, roots or branches), growth stage (e.g., green leave or foliage) and plant age (e.g., biomass from short rotation coppice or from old trees) (Liu, Wang, Karim, Sun \& Wang, 2014). Table 1 shows the shares of these biopolymers for different types and parts of selected plants. The remaining part of dry matter consists of extractives like fats and resins.

The characteristics of cellulose, hemicellulose and lignin composed of long-chained and branched hydrocarbons are shortly presented below.

- Cellulose. This biopolymer is the most frequently occurring organic substance in nature. It is built from D-glucose-subunits linked to each other via $\beta$-1,4-glycosidic bonds. Additionally, hydrogen bonds are formed since there is a large number of hydroxyl groups (OH-groups) present within the cellulose (Pérez et al., 2002). Amongst others, the micro fibrils in plant cell walls are formed in this way (Karimi, 2015).

- Hemicellulose. Hemicellulose is a collective term for many different hydrocarbon-polymers that consist of D-xylose, D-mannose, D-galactose, D-glucose, L-arabinose, 4-O-methylglucuronic, D-galacturonic, and D-glucuronic acids that are linked via $\beta-1,4-$ and partially $\beta$-1,3-glycosidic bonds. Due to the presence of branches with short lateral chains, hemicellulose is better hydrolysable, compared with cellulose (Pérez et al., 2002).

- Lignin. This heterogeneously structured biopolymer consists of 3 phenyl-propane units (p-cumaryl, coniferyl and sinapyl), whereby the basic units are connected via C-C- and aryl-ether bonds. Its heating value is higher compared to cellulose and hemicellulose (Pérez et al., 2002; Brebu \& Vasile, 2010).

\section{HEAT INDUCED DEGRADATION IN DIFFERENT ATMOSPHERES}

The heat induced pre-treatment to improve the combustion properties of lignocellulosic biomass can be realized within a gaseous as well as within a hydrothermal or vapothermal atmosphere. Hence, the impacts of such pre-treatment processes in the respective atmosphere on cellulose, hemicellulose and lignin are discussed below.

\section{Gaseous atmosphere}

Basically, while heating up the lignocellulosic biomass up to a temperature range of $300^{\circ} \mathrm{C}$, the biopolymers cellulose, hemicellulose and lignin are increasingly decomposed with growing heat supply. Nevertheless, up to roughly $150^{\circ} \mathrm{C}$, these biopolymers are still basically stable but the water included within the solid biofuels (i.e., the ligncellulosic biomass) vaporizes into the surrounding gas atmosphere. At the temperature levels exceeding about $150^{\circ} \mathrm{C}$, these biopolymers start to break up due to the dissociation of bonds; thereby, smaller molecule fragments emerge, which might leave the biomass matrix as volatile matter (so called volatiles) (Christ et al., 2017). Figure 1 shows the heat-induced degradation of cellulose, xylan (which is commonly used as a representative for hemicellulose) and lignin on

Table 1: Shares of main biopolymers in different types and parts of plants (Cortez, Demard, Bottner \& Jocteur Monrozier, 1996; Leemhuis \& de Jong, 1997)

\begin{tabular}{|l|c|c|c|c|c|}
\hline \multirow{2}{*}{ Biopolymers } & \multicolumn{2}{c|}{ Beech (Hardwood) } & \multicolumn{2}{c|}{ Pine (Softwood) } & Cotton \\
\cline { 2 - 6 } & Leaves & Wood & Needles & Wood & Straw \\
\hline Cellulose [wt.\%] & 32.4 & 49.0 & 42.6 & 45.0 & 42.0 \\
\hline Hemicellulose [wt.\%] & 23.7 & 22.0 & 22.3 & 27.5 & 12.0 \\
\hline Lignin [wt.\%] & 31.5 & 24.0 & 37.7 & 25.0 & 15.0 \\
\hline
\end{tabular}


the basis of thermogravimetric analyses within the nitrogen atmosphere.

Figure 1 indicates that the pyrolytic decomposition of the respective biopolymers takes place at different temperature ranges. This is due to the different molecular composition of these biopolymers. For instance, hemicellulose has an amorphous molecular structure with many sidebranches. These side-branches can easily be removed from the main branch already with little thermal energy or heat. Cellulose consists of a long, unbranched strand. Therefore, this biopolymer is comparatively thermally stable - at least compared to hemicellulose. Lignin consists of aromatic rings with different branches (Yang et al., 2007). Therefore, it decomposes in a wide temperature range between 100 and $600^{\circ} \mathrm{C}$ while the main decomposition of cellulose and hemicellulose occurs at the temperatures between 320 and $360^{\circ} \mathrm{C}$ and from 180 to $220^{\circ} \mathrm{C}$, respectively (Jin et al., 2013). The main reactions occurring during the heat-induced decomposition of the respective biopolymer are shortly explained below.

- Cellulose. First, bonds between the individual monomers are broken down; this results in a reduced degree of polymerization. Subsequently, decarbonylation and decarboxylation reactions take place in parallel; thereby, carbon monoxide $(\mathrm{CO})$ and carbon dioxide $\left(\mathrm{CO}_{2}\right)$ emerge into the surrounding gas phase (Antal \& Varhegyi, 1995). Then, further degradation can take place either via ring cleavage or via depolymerisation; these mechanisms can also occur in parallel (Kaltschmitt et al., 2016).

- Hemicellulose. Because of the similar polymeric structure, it is commonly assumed that the thermal degradation of hemicellulose follows the same reactions like the cellulose degradation (Patwardhan, 2010). Different authors developed the reaction schemes that also included decarbonylation, decarboxylation, dehydration and depolymerization. However, kinetic modelling or quantum chemical calculations has not validated such reaction schemes yet (Zhou et al., 2017).

- Lignin. During the thermal degradation of lignin, starting at around $100^{\circ} \mathrm{C}$, the aliphatic $\mathrm{OH}$-groups are broken up by releasing mainly $\mathrm{CO}_{2}$. At a temperature of approximately $230^{\circ} \mathrm{C}$, the aryl-alkyl-ether bonds start to crack, resulting in the formation of phenolic compounds. Additionally, the thermally induced cracking of side chains realized at these elevated temperatures can result in the formation of $\mathrm{CO}, \mathrm{CO}_{2}$, water $\left(\mathrm{H}_{2} \mathrm{O}\right)$ and formaldehyde $\left(\mathrm{CH}_{2} \mathrm{O}\right)$ even at lower temperatures. At even higher temperatures of around $400^{\circ} \mathrm{C}$ larger molecules are released as well (Evans, Milne \& Soltys, 1986).

\section{Hydrothermal / vapothermal atmosphere}

Heat-induced degradation of lignocellulosic biomass can also take place in a hydrothermal or vapothermal atmosphere. A hydrothermal atmosphere is characterized by the presence of liquid water at the temperatures above $100^{\circ} \mathrm{C}$ and shows typically an elevated pressure above $0.1 \mathrm{MPa}$. Compared to that vapothermal describes the atmosphere of saturated steam at the same temperature range. In both atmospheres, similar degradation steps take place within the biopolymers the solid biomass consists of (Funke, Reebs \& Kruse, 2013).
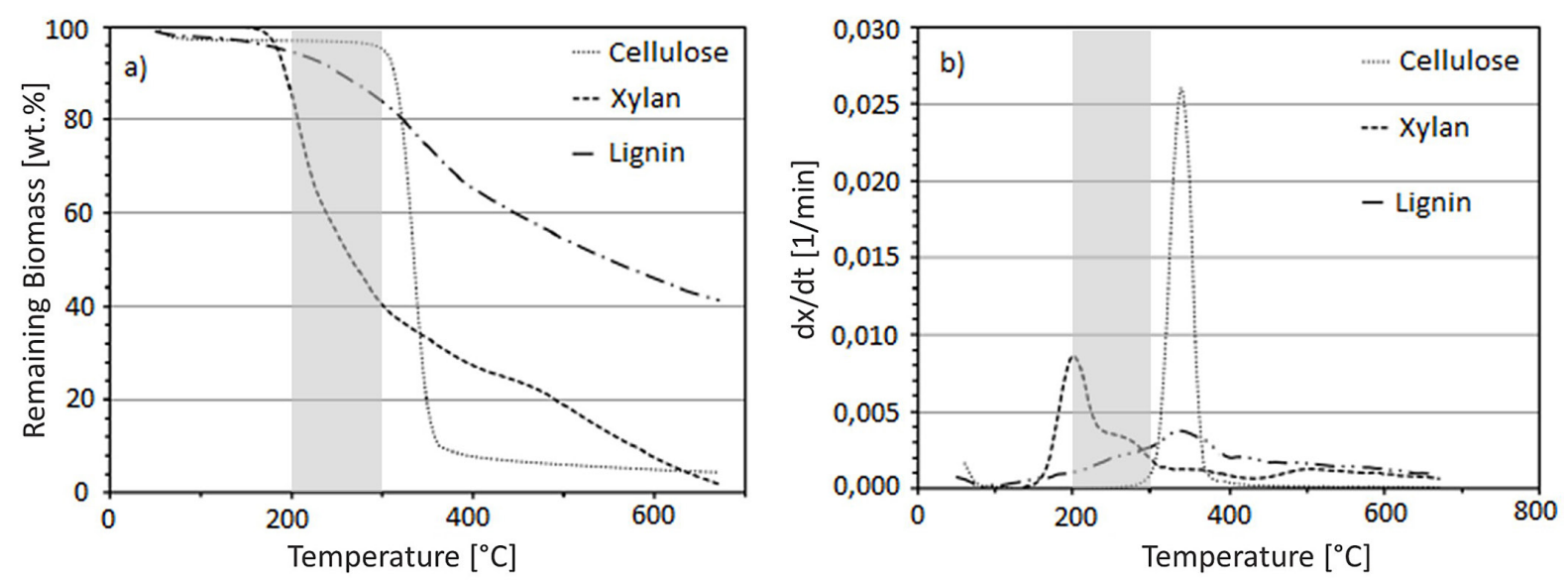

Figure 1: Thermogravimetric (a) and differential thermogravimetric analysis of cellulose, xylan and lignin (modified from (Jin, Singh \& Zondlo, 2013)) 
In order to facilitate the degradation reactions, the solid biomass has to be completely surrounded by liquid water or saturated steam (Funke \& Ziegler, 2010). Thereby, water (or steam) has various functions; e.g., parts of solid biomass dissolve and some reactions are catalysed in its presence (Akiya $\&$ Savage, 2002). Two different circumstances are mainly responsible for this phenomenon.

- With an increasing temperature level, the ionic product of water grows while increasing the concentration of hydroxyl and hydronium ions. Thereby, dehydration reactions that are catalysed by these ions are strongly influenced.

- With higher temperatures, the dielectric constant of water decreases, influencing its dissolving properties. Thereby, non-polar substances can be dissolved easier while the solubility for salts decreases (Stemann, 2013).

Furthermore, an increasing temperature and pressure level cause a decrease in water density and viscosity; this supports material transfers (Funke, 2012). Thus, the main degradation reactions within such a hydrothermal or vapothermal atmosphere are introduced below.

- Firstly, biopolymers are decomposed by the hydrolysis reactions. Thereby, macromolecules are dissolved out of the biomass matrix and broken down into their basic components. Due to lower activation energy compared to the degradation reactions taking place within a gaseous atmosphere, such reactions are executed at relatively low temperatures; e.g., hemicellulose has its maximal hydrolysis rate at around $180^{\circ} \mathrm{C}$, cellulose at around $270^{\circ} \mathrm{C}$ and lignin at around $340^{\circ} \mathrm{C}$ (Bobleter \& Binder, 1980).

- Decarboxylation reactions can occur subsequently to hydrolysis. Thereby, $\mathrm{CO}_{2}$ dissociates from the remaining molecule. Depending on the molecular structure of the starting material, this reaction can either be endothermic or exothermic (Kaltschmitt et al., 2016).

- Parallel to decarboxylation, dehydration reactions can occur as well (Coronella et al., 2014). Thereby, the atomic $\mathrm{H} / \mathrm{C}$ - and $\mathrm{O} / \mathrm{C}$ ratio decrease. As a consequence, the biomass is carbonized; i.e., related to the composition the biomass "moves" more and more towards lignite.

- Some of the components dissociated previously from the biopolymers lignin, cellulose and hemicellulose can be very reactive. This enables the highly temperature-dependent polymerization and condensation reactions to take place; e.g., dissociation of carboxyl- and hydroxyl-groups leads to the formation of unsaturated compounds that can be polymerized easily (Terres, 1952).

\section{HEAT-INDUCED PRE-TREATMENT TECHNOLOGIES}

Currently, different processes and techniques to modify the fuel properties of lignocellulosic biomass are available. Some of the best known of these techniques are shortly presented and characterized below.

\section{Torrefaction}

Torrefaction takes place within a gaseous atmosphere, usually consisting of nitrogen, to supress oxidation reactions (and thus to minimize losses) at ambient pressure. This thermal treatment process is realized at the temperatures between 200 and $300^{\circ} \mathrm{C}$ with heating rates up to $50^{\circ} \mathrm{C} / \mathrm{min}$. The maximal retention time at this temperature level is approximately $60 \mathrm{~min}$; but there are huge variations because this time period within the respective temperature level depends highly on the mechanical properties of fuel (e.g., size or particles, form of particles, moisture content). Heat input into the organic material can be realized either directly by flowing hot gas through the bulk material or indirectly by heating the reactor walls or additional fittings (Kaltschmitt et al., 2016), (Tran et al., 2013). Typically, the overarching goal of the torrefaction process is to improve the different fuel-related properties of lignocellulosic biomass such as storage properties, grindability and heating value (Acharya, Sule \& Dutta, 2012).

\section{Hydrothermal Carbonization (HTC)}

Hydrothermal carbonization takes place within a hydrothermal atmosphere in the temperature range between 180 and $250^{\circ} \mathrm{C}$ and a pressure level between 2 and $10 \mathrm{MPa}$. The retention time typically ranges between 2 and $16 \mathrm{~h}$. The realized heating time is between 60 and $75 \mathrm{~min}$ in a laboratory scale; however, there are huge variations reported in literature (e.g., (Glasner, Deerberg \& Lyko, 2011)). So far, large scale technical realization of such a hydrothermal carbonization of organic material can be carried out either 
discontinuously (with the advantage of switching input material easily) or continuously (with the advantage of a high degree of automation). The heat input into the treated biomass can be realized either directly by passing in hot steam or indirectly by heating the reactor walls or additional fittings; the technological solutions are similar to the options discussed for torrefaction (Quicker $\&$ Weber, 2016). The main goals of hydrothermal carbonization in this context are to increase the carbon content of biomass as well as to wash out incombustible components and/or impurities, unwanted due to environmental reasons (Ramke, Blöhse \& Lehman, 2012); the consequence of the latter effect is the resulting need for an environmental sound treatment of the remaining treatment water.

\section{Vapothermal Carbonization (VTC)}

Vapothermal carbonization is another option for a biomass pre-treatment. This possibility is basically a further development of the "classical" hydrothermal carbonization. Here, the heatinduced treatment takes place within a vapothermal atmosphere. Typically, the temperature range is between 180 and $250^{\circ} \mathrm{C}$ and the pressure level ranges between 2 and $10 \mathrm{MPa}$ (Funke et al., 2013). In most cases, the heat input is realized directly by passing in saturated steam into the batch reactor where the treatment takes place. Therefore, for the time being, vapothermal carbonization can only be realized discontinuously (Serfass, 2014). Compared to hydrothermal carbonization, vapothermal carbonization can be applied more effectively due to a significantly reduced amount of process water; thus the efforts to process the remaining (contaminated) water is also considerably lower (Schlitt \& Richarts, 2010). The main goal of vapothermal carbonization in this context is to increase the carbon content of biomass (to come closer to the fuel characteristics of lignite) and to improve its dewatering properties. In contrast to hydrothermal carbonization, inorganic compounds cannot be washed out; in average, which results in a relative higher ash content of the treated biomass (Minaret \& Dutta, 2016).

\section{Autoclave pre-treatment}

During the autoclave pre-treatment, the biomass with significant water content is heated up to the temperatures of 120 to $180^{\circ} \mathrm{C}$ within a closed reactor (i.e., batch system). Typically, the heat input is realized indirectly by heating the reactor walls. Thus, to reach a more or less uniform heat distribution within the biomass which is inside the reactor, mixing e.g. by a drum mixer, is necessary (Mavropoulos, 2017). During the heating up of the biomass within the reactor, the inserted biomass is firstly surrounded by a gaseous atmosphere (air containing a certain share of water vapour). Then, with increasing temperatures, the water contained inside the organic material partly evaporates while the remaining water stays in its liquid status due to the resulting increase of the pressure (i.e., the autoclave reactor is closed during the heating-up process). Thereby, a pressure increase follows the saturation vapour curve of water; afterwards, the pressure lays within a range between 0.2 and $1.0 \mathrm{MPa}$ (Scherzinger, 2017). The reaction time during autoclave pretreatment is between 1 and 5 hours. By the end of the treatment, the pressure is released suddenly by opening a valve; due to this abrupt pressure release, the water still existing inside the organic material expands and vaporises all at once, resulting in an increase of pores and partial destruction of the cell system of the treated biomass (similar to steam explosion, but most likely a bit "softer"). The main goals of the autoclave pre-treatment are to increase the heating value of biomass (e.g., by decreasing its water content or by hydrolysing low calorific fractions like hemicellulose) and to improve its storage properties.

\section{COMPARISON}

Below, the presented pre-treatment options are compared and characterized with respect to their current state of research, their market proximity, their main process parameters, their applicable educts and their product properties.

\section{Current state of research}

Figure 2 shows a quantification of published papers found in the Scopus database for the search terms "Torrefaction", "Hydrothermal Carbonization", "Vapothermal Carbonization" and "Autoclave Pre-treatment" in recent years (i.e., since 2015). Thus, most publications have been found for hydrothermal carbonization; and this trend is still clearly increasing. However, the published research on hydrothermal carbonization 
does not only focus on producing solid fuels with enhanced fuel properties but also on phosphate recovery from the solid fraction of carbonized waste materials as well as producing activated carbon for gas and water cleaning purposes (i.e., the use of the biomass as a raw material and not as an energy carrier) (Kruse \& Dahmen, 2018). The second highest number of publications was found for torrefaction. Most studies in this field aims at finding the best set of parameters for torrefaction of different types of biomass feedstock (Ribeiro et al., 2018). For autoclave pre-treatment, the amount of published papers is very limited. None of the found publications focuses on producing a solid fuel in the afore-mentioned temperature range between 120 and $180^{\circ} \mathrm{C}$. Instead, most of these publications deal with enhancing the biogas production of different types of biomass feedstock by assessing the improvement of the anaerobic digestibility of the organic matter treated within an autoclave. For vapothermal carbonization, only two publications were found since 2015. The research in this field is still at an early stage, although demonstration plants are already available.

\section{Market proximity}

In the recent years, various companies distributing the afore-mentioned techniques were incorporated. Currently, torrefaction is the most developed of these techniques. Marketable torrefaction plants are already available, most of them operating in Europe and North America (Thrän et al., 2016).
- In Europe, e.g. Blackwood Technology is one of the leading torrefaction companies, operating torrefaction plants in the Netherlands and in Finland (Blackwood Technology B.V., 2019).

- In North America, for example, Airex Energy is operating an industrial-scale torrefaction plant in Quebec, Canada (Airex Energy, 2019).

Compared with torrefaction, hydrothermal carbonization is not that far from being introduced to the market. In 2017 the largest hydrothermal carbonization plant was put into operation by AVA GmbH in Germany. Further plants are planned to be built within the next years, especially in China (Alt, 2017). Additionally, the company TerraNova Energy is operating an industrial-scale hydrothermal carbonization plant in Jining, China (Agrokarbo, 2017).

As of yet, vapothermal carbonization is only available in demonstration scale. KS-VTCtech $\mathrm{GmbH}$, for instance, is operating a vapothermal carbonization demonstration plant in Rudong, China (Quicker \& Weber, 2016). Furthermore, Revatec GmbH holds patents for a special vapothermal carbonization process which is planned to be tested in a large scale (Revatec GmbH, 2011). Autoclave pre-treatment is the least developed of the afore-mentioned techniques. At the moment, only the research on upgrading various types of biomass is conducted at various universities.

\section{Process parameters}

Figure 3 shows a comparison and classification of the afore-mentioned pre-treatment technologies related to typical selected process parameters

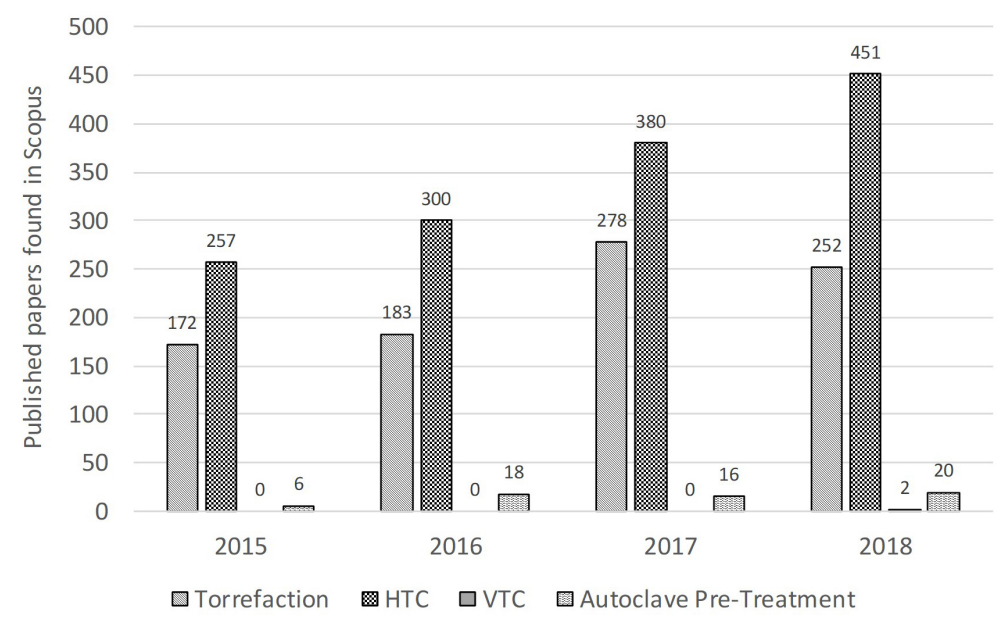

Figure 2: Published papers found in the Scopus database for the search terms "Torrefaction", "Hydrothermal Carbonization (HTC)", "Vapothermal Carbonization (VTC)" and "Autoclave Pre-Treatment" 
(surrounding atmosphere, temperature, pressure, reaction time).

Hereinafter, the different processes are discussed regarding their process parameters. The focus is on describing the resulting changes.

- Torrefaction. Below, this pre-treatment process is discussed in detail.

- Torrefaction can be performed either within a gaseous atmosphere dominated by either air or nitrogen. However, within an oxygencontaining atmosphere (e.g., ambient air is used within the gaseous atmosphere) there is the risk of carbon losses due to the oxidation of organic carbon contained within the lignocellulosic biomass into $\mathrm{CO}$ and $\mathrm{CO}_{2}$, which could result in significant energy losses. This is the reason why typically a nitrogen atmosphere is realized in technical processes.

- Within the temperature range at which such a torrefaction is typically realized (200 to $300^{\circ} \mathrm{C}$ ) mainly hemicellulose is thermally degraded. The other biopolymers contained within lignocellulosic biomass are typically only affected to a limited extent or even untouched.

- The typical retention time during torrefaction is relatively short, ranging from few minutes to $1 \mathrm{~h}$; if larger biomass pieces are to be torrefied, the treatment time might be longer. This is sufficient to realize such a partial degradation of the biopolymers contained within the organic material. Longer retention times would lead to stronger degradation resulting in lower solid yield, which is undesired when producing a solid fuel (Wannapeera, Fungtammasan \& Worasuwannarak, 2011).

- Torrefaction normally takes place under atmospheric pressure. Yet, there are only few studies available investigating the influence of pressure on the heat-induced degradation processes as well as on the torrefaction products. Nevertheless, a study on the torrefaction of woody biomass shows that an increase in pressure could result in higher solid yield as well as in average a higher carbon content and a lower oxygen content of the pressurized torrefied product, compared to the product provided under ambient pressure; this could result in a higher energy content of the final product (Wannapeera \& Worasuwannarak, 2012).

- Hydrothermal carbonization. According to the procedure realized above, hydrothermal carbonisation is also assessed below.

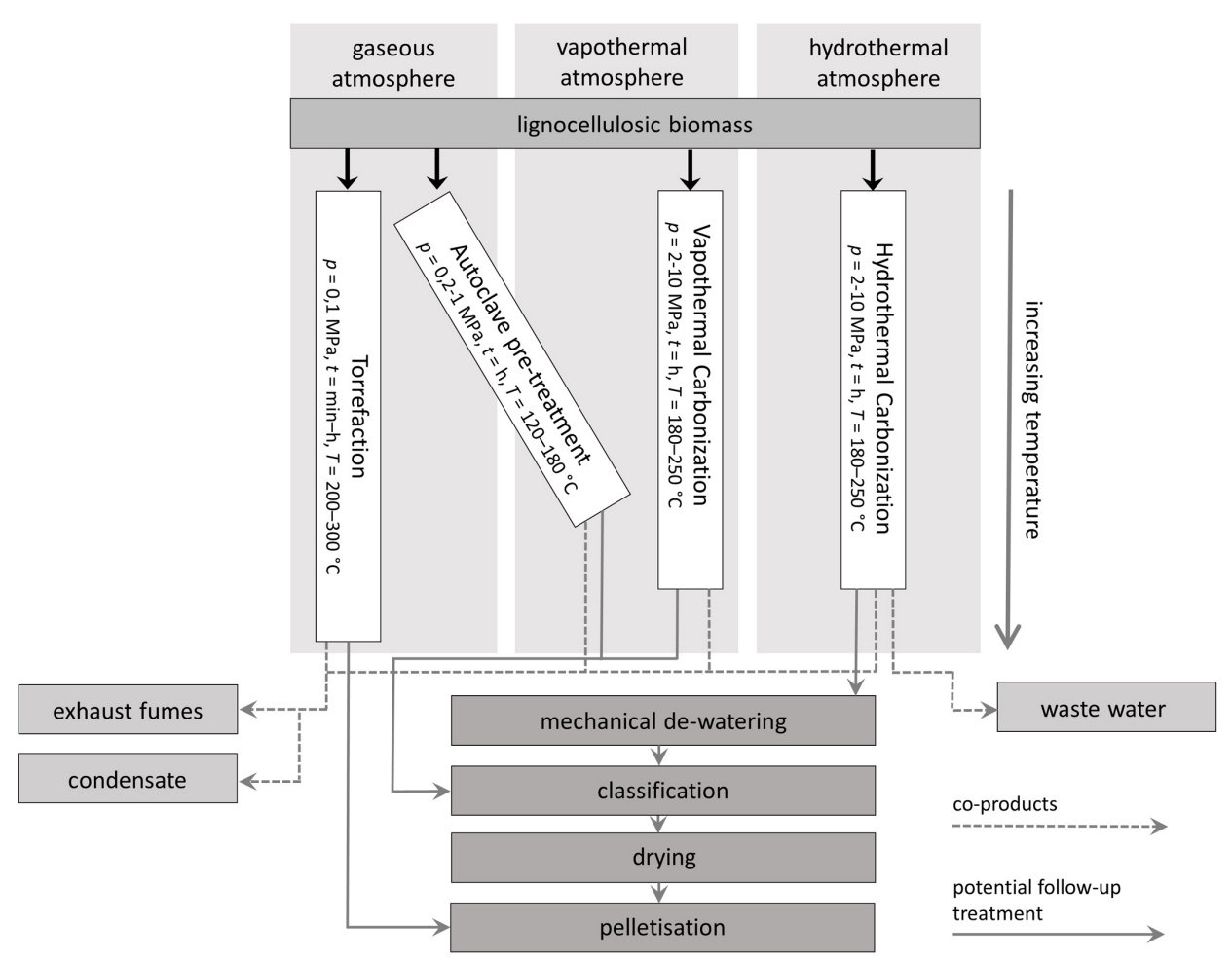

Figure 3: Classification of heat induced pre-treatment technologies regarding selected process parameters $(\mathrm{p}=$ pressure, $\mathrm{t}=$ reaction time, $\mathrm{T}=$ temperature $)$ 
- Hydrothermal carbonization takes place in liquid, subcritical water. This enables hydrolysis reactions to occur.

- Temperature constitutes the main influencing parameter the hydrothermal carbonization. In the temperature range (180 to $250^{\circ} \mathrm{C}$ ) where this process is typically realized, hemicellulose as well as cellulose can be hydrolysed. Subsequently, decarboxylation, dehydration, polymerization and condensation reactions (chapter 3.2) can occur.

- Reaction time is another important process parameter. Longer reaction times lead to higher degree of carbonization and therefore higher energy density of the solid product. Unfortunately, longer reaction time also leads to a decrease in solid yield so that a techno-economic compromise has to be found (Mäkelä, Benavente \& Fullana, 2015).

- Pressure does not strongly influence the characteristics of the solid product, but has to be high enough to enable a liquid phase in the respective temperature range (Kaltschmitt et al., 2016).

- Vapothermal carbonization. This pre-treatment process is presented and analysed in detail below, according to the same assessment criteria.

- Vapothermal carbonization takes place in a saturated steam atmosphere. The total amount of surrounding water is much lower compared to the processes in a hydrothermal atmosphere, but nevertheless, hydrolysis reactions can occur.

- Vapothermal carbonization takes place at the same temperature as the hydrothermal carbonization $\left(180\right.$ to $\left.250^{\circ} \mathrm{C}\right)$. Thereby, the heat-induced degradation is similar to the processes occurring at hydrothermal carbonization (see above). Although the process is similar, there are some differences reported; e.g., fewer hydrophilic, oxygencontaining functional groups are degraded during the vapothermal carbonization (Shafie, Al-attab \& Zainal, 2018).

- Reaction time during vapothermal carbonization is also in the same range like in the case of hydrothermal carbonization. However, since vapothermal carbonization takes place in an atmosphere consisting of saturated steam, the heating phase can technically be reduced, resulting in shorter total retention times.

- Pressure during vapothermal carbonization is used to reach the desired process temperature. Similarly to hydrothermal carbonization, it is assumed that pressure does not strongly influence the characteristics of the solid product.

- Autoclave pre-treatment. Autoclave pretreatment, as a pre-treatment process for lignocellulosic biomass, remains mostly unexplored. Nevertheless, the most important facts available so far are summarized below.

- Autoclave pre-treatment starts in a surrounding gas atmosphere. During heating up, the water contained within the biomass evaporates; this leads to a surrounding atmosphere of saturated steam within the closed batch reactor at the temperatures above $100 \mathrm{C}$. Such an atmosphere enables the hydrolysis reactions to occur.

- The process temperatures of 120 to $180^{\circ} \mathrm{C}$ where the autoclave treatment is commonly realized are comparatively low. Nevertheless, degradation reactions can occur during the autoclave pre-treatment due to the surrounding vapothermal atmosphere. This mainly affects hemicellulose, which can be hydrolysed starting at around $150^{\circ} \mathrm{C}$.

- Reaction time during autoclave pre-treatment has not been investigated so far, but most likely, it is oriented to reaction kinetics. This means, longer reaction times lead to stronger degradation reactions.

- Pressure can be an important parameter during autoclave pre-treatment. By suddenly releasing pressure, the water inside the biomass evaporates, which could destroy the biomass structure (steam explosion effect). Depending on the type of biomass and the liquid water contained within the organic material, this could greatly influence the mechanical properties of fuel.

\section{Applicable educts}

While applying the afore-mentioned pretreatment techniques, the used educts can differ vastly. In general, the lignocellulosic biomass with high moisture content is well-suited for the processes in hydrothermal or vapothermal atmosphere, while dry biomass should rather be 
treated in a gaseous atmosphere in order to increase the overall energy efficiency (Kaltschmitt et al., 2016). Typical examples for naturally occurring (relatively) dry biomasses are wood and stalk-type biomass; typical wet biomass is, e.g. organic waste streams from the food processing industry and/or from waste water treatment like sewage sludge. Figure 4 shows the recommendations based on the educt moisture content.

Therefore (and considering further plantrelated reasons), the following subdivision of educts can be made:

- Torrefaction. Machine-chipped wood or stalk type biomass with low moisture content is most suitable for a treatment via torrefaction (Chen et al., 2011).

- Hydrothermal carbonization. Biomass has to be in a pumpable state in order to realize hydrothermal carbonization. In order to ensure complete wetting, mostly wet organic residues like manure or sewage sludge are used. In principle, it is also possible to use other types of biomass; this would require additional process steps like comminution and addition of water (Greve, 2016).

- Vapothermal carbonization. Moist and chunky biomass like domestic biowaste, as well as non-dried cultivated biomass, is suitable for a treatment via vapothermal carbonization. The possibility of co-treating foreign matter without disrupting the process is an advantage of this pre-treatment; these impurities can be separated afterwards (Quicker \& Weber, 2016; Serfass, 2014).

- Autoclave pre-treatment. For autoclave pretreatment, similar educts like for vapothermal carbonization can be used. Due to the fact that no saturated steam is additionally supplied, the moisture content of an educt has to be above $50 \mathrm{wt} .-\%$ in order to generate the surrounding vapothermal atmosphere.

\section{Product properties}

The product properties of the different pretreatment techniques are different even due the fact that all afore-mentioned techniques aim at providing a solid biofuel with defined properties. Thereby, the product properties can vary due to the use of different types of educts and different process parameters (chapter 5.1).

- Torrefaction. Pre-treatment by torrefaction does not (or just hardly) change the biomass shape; the biomass structure can therefore still easily be recognized after torrefaction. Nevertheless, due to outpouring gases, the solid biomass becomes more porous, which results in lower bulk density, as well as a clearly improved grindability (Tumuluru et al., 2011). Furthermore, due to heating-up during torrefaction, the water content of the organic matter decreases. The equilibrium moisture content, which is an indicator for hydrophobicity, also decreases due to the loss of hydroxyl groups from cellulose and hemicellulose (Chen et al., 2015). Additionally, the final product is characterized by a higher ash content compared to the educt, due to the loss of organic matter. Nevertheless, the heating value increases, because the substances released during the pretreatment process are mostly characterized by relatively high oxygen contents; the latter hardly contributes to the heating value of the biomass (Tumuluru et al., 2011).

- Hydrothermal carbonization. The products resulting from hydrothermal carbonization are more porous compared to the used educt, which can be seen by visual enlargement (Ramke \& Blöhse, 2010). This results in a lower bulk density at the same particle size after dewatering. Nevertheless, the original structure of the biomass can still be easily recognized after hydrothermal carbonization. The

$$
\begin{aligned}
& \text { Torrefaction } \\
& \text { Vapothermal Carbonisation } \\
& \text { Autoclave pre-treatment } \\
& \text { Hydrothermal Carbonization }
\end{aligned}
$$

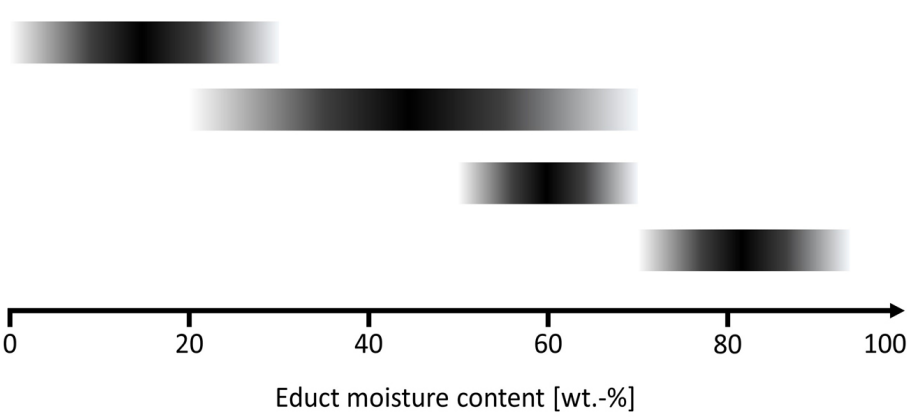

Figure 4: Recommendation for the application of different pre-treatment techniques based on educt water content 
decrease in hydrophilic functional groups during the process facilitates the mechanical dewatering and thermal drying. Furthermore, the hydrothermal carbonization products show a higher energy content compared to their educt, because the oxygen- and hydrogen-content decreases (i.e., relative increase of the carbon content) (Luque, Campelo \& Clark, 2011). Moreover, lightly adhesive foreign particles, as well as inorganic material eventually enclosed within the biomass, can be detached during hydrothermal carbonization; this results in a comparatively lower ash content (Reza et al., 2013).

- Vapothermal carbonization. Similarly to hydrothermal carbonization, the biomass structure can still be recognized for vapothermal carbonization products. Nevertheless, porosity increases considerably. Even though there is no addition of liquid water during vapothermal carbonization, the products provided after this pre-treatment are characterized by increased water content before drying takes place; this results from the introduction of saturated steam during the process. Compared to hydrothermal carbonization, this increase is lower, so that the mechanical dewatering is not mandatory (Schwark, 2016). Through vapothermal carbonization, the drying behaviour of the product increases compared to the educt. This is an indicator for degradation of cell wall components, which results in releasing bound water from the biomass (Shafie et al., 2018). Furthermore, the same functional groups as during hydrothermal carbonization are disintegrated. The resulting consequences are higher hydrophobicity and increased energy density (Schwark, 2016) (Funke et al., 2013). Compared to hydrothermal carbonization, the adhesive particles are not removed during vapothermal carbonization. Since more organic than inorganic compounds are removed during vapothermal carbonization, the products are characterized by a higher ash content, compared to their educts (Schwark, 2016).

- Autoclave pre-treatment. After autoclave pretreatment, the biomass structure is still visible as well. Further research has to be carried out to analyse how biomass cells are destroyed during the pressure release (i.e., steam explosion effect). Since there is no addition of water during the autoclave pre-treatment, the product has lower water content, compared to the respective educt, because of the evaporation of water as a consequence of the heating-up during this pre-treatment process. Nevertheless, to produce a solid fuel, the product has to be dried. At the temperatures over $150^{\circ} \mathrm{C}$, a reduction of hemicellulose has been observed. This results in higher energy density, compared to the untreated biomass, because relatively more lignin with a higher energy content remains within the product. Furthermore, lower equilibrium moisture contents have been measured for the products pre-treated at this temperature range, which could be due to heat induced degradation of hydrophilic functional groups.

Table 2 classifies the changes of different important biomass characteristics that are to be improved by the respective pre-treatment technique. It can be seen that both torrefaction and hydrothermal carbonization can significantly increase heating value, grindability and hydrophobicity of the used educt. Due to the fact that inorganics can be washed out, hydrothermal carbonization can also decrease the ash content (and produce contaminated water to be further treated). In turn, the torrefaction increases the ash content. This is also true for vapothermal carbonization. Additionally, it has been observed that the positive effect on grindability is lower for vapothermal carbonization, compared to hydrothermal carbonization. For autoclave pre-treatment, no data is yet available for the effect on grindability. Nevertheless, the first results show an increase in heating value, hydrophobicity and ash content.

Table 2: Assessment of the change of different biomass characteristics by the respective pre-treatment techniques (Minaret \& Dutta, 2016; Shafie et al., 2018; Reza et al., 2013; Reza et al., 2014; Al-Wabel et al., 2018; Álvarez et al., 2018; Wang et al., 2018; Kambo \& Dutta, 2014)

\begin{tabular}{|l|c|c|c|c|}
\hline \multicolumn{1}{|c|}{ Pre-treatment techniques } & Heating value & Grindability & Hydrophobicity & Ash content \\
\hline Torrefaction & $\uparrow$ & $\uparrow$ & $\uparrow$ & $\lambda$ \\
\hline Hydrothermal carbonisation & $\uparrow$ & $\uparrow$ & $\uparrow$ & $\searrow$ \\
\hline Vapothermal carbonisation & $\uparrow$ & $\lambda$ & $\uparrow$ & $\lambda$ \\
\hline Autoclave pre-treatment & $\lambda$ & $\mathrm{N} / \mathrm{A}$ & $\lambda$ & $\lambda$ \\
\hline
\end{tabular}

个: high increase $\quad \pi$ : low increase $\quad У$ :low decrease $\quad$ N/A: no data available 


\section{CONCLUSIONS}

Some biomass properties, e.g. low heating value and hydrophilicity, complicate its use as a solid fuel. The thermal processes to improve the biomass fuel properties can be realized in different atmospheres (hydrothermal, vapothermal, gaseous) at different temperatures. Therefore, four different techniques were described and characterized, namely torrefaction, hydrothermal carbonization, vapothermal carbonization and autoclave pre-treatment. The main findings can be summarized as follows.

- In order to achieve similar results related to the fuel properties within a gaseous atmosphere, higher temperatures but lower reaction times are required compared to the processes in vapothermal or hydrothermal atmosphere.

- Only one of the pre-treatment techniques assessed here (torrefaction) is currently marketready. All the others are still in an early (autoclave pre-treatment) or advanced R\&D phase; for example, a lot of research has been carried out especially for hydrothermal carbonization and only limited research activities have been realized for vapothermal carbonization.

- The selection of the most suitable pre-treatment technique should be based on the biomass properties. The biomass in a liquid state should preferably be treated in a hydrothermal atmosphere, while the dry biomass should be treated in a gaseous atmosphere. Relatively moist biomass can be treated in a vapothermal atmosphere.

All over, these various pre-treatment options address different types of biomass. Thus, if biomass and especially organic side and waste streams are to be used in the years to come to prove climate neutral energy within the global energy system, all options are most likely needed to lock-up these potentials for an economically viable, environmentally sound and socially acceptable energy provision.

\section{REFERENCES}

1. Acharya, B., Sule, I. \& Dutta, A. (2012). A review on advances of torrefaction technologies for biomass processing. Biomass Conversion and Biorefinery, 2(4), 349-369. doi: 10.1007/s13399-012-0058-y.

2. Agrokarbo (2017). Phosphor-Rückgewinnung mit HTC in China. http://www.agrokarbo.info/terranova-china/ (06.02.2019).
3. Airex Energy (2019). A clean alternative to coal. http://www.airex-energy.com/en/biocoal (06.02.2019).

4. Akiya, N. \& Savage, P.E. (2002). Roles of Water for Chemical Reactions in High-Temperature Water. Chemical Reviews, 102(8), 2725-2750. doi: 10.1021/cr000668w.

5. Alt, F. (2017). Weltweit größte Biokohleanlage in Betrieb genommen. http://www.sonnenseite.com/ de/energie/weltweit-groesste-biokohleanlage-inbetrieb-genommen.html (06.02.2019).

6. Álvarez, A., Nogueiro, D., Pizarro, C., Matos, M. \& Bueno, J.L. (2018). Non-oxidative torrefaction of biomass to enhance its fuel properties. Energy, 158, 1-8. doi: 10.1016/j.energy.2018.06.009.

7. Al-Wabel, M.I., Rafique, M.I., Ahmad, M., Ahmad, M., Hussain, A. \& Usman, A.R.A. (2018). Pyrolytic and hydrothermal carbonization of date palm leaflets: Characteristics and ecotoxicological effects on seed germination of lettuce. Saudi Journal of Biological Sciences. doi: 10.1016/j.sjbs.2018.05.017.

8. Antal, M.J. \& Varhegyi, G. (1995). Cellulose Pyrolysis Kinetics: The Current State of Knowledge. Industrial \& Engineering Chemistry Research(34), 703-717. doi: 10.1021/ie00042a001.

9. Blackwood Technology B.V. (2019). Enabling the large scale use of biomass for green energy. http:// www.blackwood-technology.com/ (06.02.2019).

10. Bobleter, O. \& Binder, H. (1980). Dynamischer hydrothermaler Abbau von Holz. Holzforschung(34), 48-51.

11. Brebu, M. \& Vasile, C. (2010). Thermal Degradation of Lignin - A Review. Cellulose Chemistry and Technology (44), 353-363.

12. Chen, D., Zheng, Z., Fu, K., Zeng, Z., Wang, J. \& Lu, M. (2015). Torrefaction of biomass stalk and its effect on the yield and quality of pyrolysis products. Fuel, 159, 27-32. doi: 10.1016/j.fuel.2015.06.078.

13. Chen, W.-H., Hsu, H.-C., Lu, K.-M., Lee, W.-J. \& Lin, T.-C. (2011). Thermal pretreatment of wood (Lauan) block by torrefaction and its influence on the properties of the biomass. Energy, 36 (5), 30123021. doi: 10.1016/j.energy.2011.02.045.

14. Christ, D., Scherzinger, M., Neuling, U. \& Kaltschmitt, M. (2017). Thermochemical Conversion of Solid Biofuels: Processes and Techniques In (Ed.) R. A. Meyers, Encyclopedia of Sustainability Science and Technology (pp. 1-22). Springer New York.

15. Coronella, C.J., Lynam, J.G., Reza, M.T. \& Uddin, M.H. (2014). Hydrothermal Carbonization of Lignocellulosic Biomass In (Ed.) F. Jin, Application of Hydrothermal Reactions to Biomass Conversion (pp. 275-311). Springer Berlin Heidelberg.

16. Cortez, J., Demard, J.M., Bottner, P. \& Jocteur Monrozier, L. (1996). Decomposition of mediterranean 
leaf litters: A microcosm experiment investigating relationships between decomposition rates and litter quality(28), 443-452.

17. Evans, R.J., Milne, T.A. \& Soltys, M.N. (1986). Direct Mass-Spectrometric Studies Of The Pyrolysis Of Carbonaceous Fuels: III. Primary Pyrolysis Of Lignin. Journal of Analytical and Applied Pyrolysis (9), 207-236.

18. Funke, A. (2012). Hydrothermale Karbonisierung von Biomasse: Reaktionsmechanismen und Reaktionswärme. doi: 10.14279/depositonce-3303.

19. Funke, A., Reebs, F. \& Kruse, A. (2013). Experimental comparison of hydrothermal and vapothermal carbonization. Fuel Processing Technology, 115, 261-269. doi: 10.1016/j.fuproc.2013.04.020.

20. Funke, A. \& Ziegler, F. (2010). Hydrothermal carbonization of biomass: A summary and discussion of chemical mechanisms for process engineering. Biofuels, Bioproducts \& Biorefining (4), 160-177. doi: $10.1002 / \mathrm{bbb}$.

21. Glasner, C., Deerberg, G. \& Lyko, H. (2011). Hydrothermale Carbonisierung: Ein Überblick. Chemie Ingenieur Technik, 83 (11), 1932-1943. doi: 10.1002/cite. 201100053 .

22. Greve, T. (2016). Hydrothermale Carbonisierung von Landschaftspflegematerial: Parameteranalyse und Methodenentwicklung in Richtung einer Prozessmodellierung.

23. IEA - International Energy Agency (2017). Key World Energy Statistics.

24. Tumuluru, J.S., Sokhansanj, S., Hess J.R., Wright, C.T. \& Boardman R. D. (2011). A review on biomass torrefaction process and product properties for energy applications. Industrial Biotechnology, 384-409. doi: 10.1089/ind.

25. Jin, W., Singh, K. \& Zondlo, Z. (2013). Pyrolysis Kinetics of Physical Components of Wood and WoodPolymers Using Isoconversion Method. Agriculture (3), 12-32. doi: 10.3390/agriculture3010012.

26. Kaltschmitt, M., Hartmann, H. \& Hofbauer, H. (2016). Energie aus Biomasse: Grundlagen, Techniken und Verfahren. Springer Vieweg.

27. Kambo, H.S. \& Dutta, A. (2014). Strength, storage, and combustion characteristics of densified lignocellulosic biomass produced via torrefaction and hydrothermal carbonization. Applied Energy, 135, 182-191. doi: 10.1016/j.apenergy.2014.08.094.

28. Karimi, K. (2015). Lignocellulose-based bioproducts. Biofuel and Biorefinery Technologies, Springer International Publishing Switzerland.

29. Kruse, A. \& Dahmen, N. (2018). Hydrothermal biomass conversion: Quo vadis? The Journal of Supercritical Fluids, 134, 114-123. doi: 10.1016/j. supflu.2017.12.035.

30. Leemhuis, R.J. \& de Jong, R.M. (1997). Biomassa: biochemische samenstelling en conversiemethoden, Petten.

31. Liu, C., Wang, H., Karim, A.M., Sun, J. \& Wang, Y. (2014). Catalytic fast pyrolysis of lignocellulosic biomass. Chemical Society reviews, 43 (22), 7594 7623. doi: 10.1039/c3cs60414d.

32. Luque, R., Campelo, J. \& Clark, J. (2011). Handbook of biofuels production: Processes and technologies. Woodhead Publishing Limited.

33. Mäkelä, M., Benavente, V., \& Fullana, A. (2015). Hydrothermal carbonization of lignocellulosic biomass: Effect of process conditions on hydrochar properties. Applied Energy, 155, 576-584. doi: 10.1016/j.apenergy.2015.06.022.

34. Mavropoulos, A. (2017). Bioelektra: a new promising technology. https://wastelessfuture.com/bioelektra-a-new-promising-technology/ (18.01.2019).

35. Minaret, J. \& Dutta, A. (2016). Comparison of liquid and vapor hydrothermal carbonization of corn husk for the use as a solid fuel. Bioresource technology, 200, 804-811. doi: 10.1016/j.biortech.2015.11.010.

36. Patwardhan, P.R. (2010). Understanding the product distribution from biomass fast pyrolysis.

37. Pérez, J., Muñoz-Dorado, J., La Rubia, T. de, \& Martínez, J. (2002). Biodegradation and biological treatments of cellulose, hemicellulose and lignin: An overview. International microbiology: the official journal of the Spanish Society for Microbiology, 5 (2), 53-63. doi: 10.1007/s10123-002-0062-3.

38. Quicker, P. \& Weber, K. (2016). Biokohle: Herstellung, Eigenschaften und Verwendung von Biomassekarbonisaten. Springer Vieweg.

39. Ramke, H.G., Blöhse, D. \& Lehman, H.J. (2012). Wissenschaftlich-technische Grundlagen der Hydrothermalen Carbonisierung organischer Siedlungsabfälle: Hydrothermal Carbonization of Organic Municipal Solid Waste - Scientific and Technical Principles (9), 476-483.

40. Ramke, H.-G. \& Blöhse, D. (2010). Analytik von Biokohle aus Hydrothermaler Carbonisierung von Biomasse. Fachgespräch Feststoffuntersuchung 2010 - Neue Entwicklungen in der Abfall- und Altlastenuntersuchung.

41. RevatecGmbH(2011). VapothermaleCarbonisierung (VTC) - Revatec-Verfahren. http://revatec.de/vapothermale_carbonisierung.htm (06.02.2019).

42. Reza, M.T., Lynam, J.G., Uddin, M.H. \& Coronella, C.J. (2013). Hydrothermal carbonization: Fate of inorganics. Biomass and Bioenergy, 49, 86-94. doi: 10.1016/j.biombioe.2012.12.004.

43. Reza, M.T., Uddin, M.H., Lynam, J.G. \& Coronella, C.J. (2014). Engineered pellets from dry torrefied and HTC biochar blends. Biomass and Bioenergy, 63, 229-238. doi: 10.1016/j.biombioe.2014.01.038.

44. Ribeiro, J., Godina, R., Matias, J. \& Nunes, L. 
(2018). Future Perspectives of Biomass Torrefaction: Review of the Current State-Of-The-Art and Research Development. Sustainability, 10 (7), 2323. doi: 10.3390/su10072323.

45. Scherzinger, M. (2017), Optimierung der thermischen Biomassenutzung durch Autoklavierung. Leipzig.

46. Schlitt, R. \& Richarts, F. Verfahren und Vorrichtung zur Carbonisierung von Biomasse mit Dampfsteuerung (EP 2410035 A1).

47. Schwark, J. (2016). Vergleichende Analyse der Produkte aus HTC und VTC unter besonderer Berücksichtigung von Gärreststoff als Edukt.

48. Serfass, K. (2014), Hydrothermale Carbonisierung. Stand der Technik und Anwendungsbeispiele. Kalkar, Kalkar.

49. Shafie, S.A., Al-attab, K.A. \& Zainal, Z.A. (2018). Effect of hydrothermal and vapothermal carbonization of wet biomass waste on bound moisture removal and combustion characteristics. Applied Thermal Engineering, 139, 187-195. doi: 10.1016/j. applthermaleng.2018.02.073.

50. Stemann, J. (2013). Hydrothermale Carbonisierung: Stoffliche und energetische Kreislaufführung.

51. Terres, E. (1952). Über die Entwässerung und Veredlung von Rohtorf und Rohbraunkohle. Brennstoffchemie (33), 1-12.

52. Thrän, D., Witt, J., Schaubach, K., Kiel, J., Carbo, M., Maier, J., Ndibe, C., Koppejan, J., Alakangas, E., Majer, S. \& Schipfer, F. (2016). Moving torrefaction towards market introduction - Technical improve- ments and economic-environmental assessment along the overall torrefaction supply chain through the SECTOR project. Biomass and Bioenergy, 89, 184-200. doi: 10.1016/j.biombioe.2016.03.004.

53. Tran, K.-Q., Luo, X., Seisenbaeva, G. \& Jirjis, R. (2013). Stump torrefaction for bioenergy application. Applied Energy, 112, 539-546. doi: 10.1016/j. apenergy.2012.12.053.

54. Wang, L., Barta-Rajnai, E., Skreiberg, Ø., Khalil, R., Czégény, Z., Jakab, E., Barta, Z. \& Grønli, M. (2018). Effect of torrefaction on physiochemical characteristics and grindability of stem wood, stump and bark. Applied Energy (227) 137-148. doi: 10.1016/j.apenergy.2017.07.024.

55. Wannapeera, J., Fungtammasan, B., \& Worasuwannarak, N. (2011). Effects of temperature and holding time during torrefaction on the pyrolysis behaviours of woody biomass. Journal of Analytical and Applied Pyrolysis, 92, 99-105. doi: 10.1016/j. jaap.2011.04.010.

56. Wannapeera, J. \& Worasuwannarak, N. (2012). Upgrading of woody biomass by torrefaction under pressure. Journal of Analytical and Applied Pyrolysis, 96, 173-180. doi: 10.1016/j.jaap.2012.04.002.

57. Yang, H., Yan, R., Chen, H., Lee, D.H. \& Zheng, C. (2007). Characteristics of hemicellulose, cellulose and lignin pyrolysis. Fuel, 86, 1781-1788. doi: 10.1016/j.fuel.2006.12.013.

58. Zhou, X., Li, W., Mabon, R., \& Broadbelt, L.J. (2017). A Critical Review on Hemicellulose Pyrolysis. Energy Technology, 1 (5), 52-79. doi: 10.1002/ ente. 201600327. 